\title{
Analyzing science education in the U.K.: taking a system-wide approach
}

Article

Accepted Version

Falk, J., Dierking, L., Osborne, J., Wenger, M., Dawson, E. and Wong, B. (2015) Analyzing science education in the U.K.: taking a system-wide approach. Science Education, 99 (1). pp. 145-173. ISSN 0036-8326 doi:

https://doi.org/10.1002/sce.21140 Available at https://centaur.reading.ac.uk/70030/

It is advisable to refer to the publisher's version if you intend to cite from the work. See Guidance on citing.

To link to this article DOI: http://dx.doi.org/10.1002/sce.21140

Publisher: Wiley

All outputs in CentAUR are protected by Intellectual Property Rights law, including copyright law. Copyright and IPR is retained by the creators or other copyright holders. Terms and conditions for use of this material are defined in the End User Agreement.

\section{www.reading.ac.uk/centaur}

\section{CentAUR}

Central Archive at the University of Reading 
Reading's research outputs online 
This preprint copy is an accepted manuscript of the paper published in Science Education in 2015. Please cite as:

Falk, J. H., Dierking, L. D., Osborne, J., Wenger, M., Dawson, E., \& Wong, B. (2015). Analyzing Science Education in the United Kingdom: Taking a System-Wide Approach. Science Education, 99(1), 145-173. doi:10.1002/sce.21140

http://onlinelibrary.wiley.com/doi/10.1002/sce.21140/epdf

\section{Analyzing Science Education in the United Kingdom: Taking a System-Wide Approach}

JOHN H. FALK, ${ }^{1}$ LYNN D. DIERKING, ${ }^{1}$ JONATHAN OSBORNE, ${ }^{2}$ MATTHEW WENGER, ${ }^{1}$ EMILY DAWSON ${ }^{3}$ BILLY WONG ${ }^{3}{ }^{1}$ College of Education, Oregon State University, Corvallis, OR 97331, USA; ${ }^{2}$ College of Education, Stanford University, Palo Alto, CA 94305, USA; ${ }^{3}$ Department of Education \& Professional Studies, King's College London, London SE1 9NH, UK

Correspondence to: John Falk; e-mail: falkj@science.oregonstate.edu 


\begin{abstract}
Increasing evidence suggests that individuals develop their understanding of science concepts in and out of school, using varied community resources and networks. Thus in contrast to historic research approaches that focus exclusively on single organizations and/or educational events, the current paper presents exploratory research in which we utilized specific community ecology analytical tools and approaches to describe and analyze the U.K. science education community as a whole. Data suggest that overall the U.K. science education community is highly interconnected, and collaborative within individual sectors and moderately interconnected and collaborative between sectors; schools and to a lesser degree universities were outliers to this pattern. An important conclusion was that management to maximize the effectiveness of science education the U.K. science education community would involve support for continued diversification of the number of science education entities in the system and encouragement of reciprocally collaborative, synergistic relationships. We posit that systemic research enables a broader, more comprehensive view of a system's strengths and weaknesses, offering useful insights into the structure and functioning of science education activities; insights that could help researchers, practitioners, and policy makers improve the overall quality of science education delivery for all.
\end{abstract}


Today's youth and adults live and learn within a variety of settings and configurations that include the home, schools, informal/free-choice learning organizations and institutions, and workplace environments, all shaped by a continuous stream of emerging scientific and technological innovations and mediated by rapidly evolving digital media. Collectively, these resources form a complex, community-learning infrastructure. However, communities, and the complex learning infrastructure of intersecting educational entities they contain, are not mere "backdrops" for science learning; they are dynamic learning environments in which people engage, interact, and make sense of the science they encounter in their daily lives (Barab \& Kirshner, 2001). There is increasing evidence that individuals develop their un- derstanding of science concepts in and out of school using a variety of community resources and networks through an accumulation of experiences from different sources at different times (e.g., Barron, 2006; Bathgate, Schunn, \& Corenti, 2014; Bell, Lewenstein, Shouse, \& Feder, 2009; Falk \& Needham, 2013; Horrigan, 2006; Hupbach, Hardt, Gomez, \& Nadel, 2008; Ito et al., 2013; Korpan, Bisanz, Boehme, \& Lynch, 1997; Lemke, Lecusay, Cole, \& Michalchik, 2012, Organization for Economic Co-operation and Development [OECD], 2012; National Science Board, 2012; Stocklmayer, Rennie, \& Gilbert, 2010; Tal \& Dierk- ing, 2014). The result is that the boundaries of when, where, why, how, and with whom people learn science are becoming increasingly blurred.

Despite the increasing evidence that individuals pursue scientific interests and develop understandings across the day and throughout a lifetime, current approaches to analyzing science education efforts rarely consider the theoretical or methodological implications of these findings for research, practice, or policy. Most educational research and development efforts are not planned nor designed to consider the multidimensional, dynamic, and complex qualities of a robust community-wide system. Instead, they focus on documenting the individual activities and outcomes of specific educational entities (e.g., schools, science centers, digital media, after-school programs), typically over relatively brief time frames. This research has provided valuable insights into the contributions of individual educational entities to science learning. However, such focused efforts fail to account for the totality and extent of the contingent, lifelong, and diverse learning opportunities that exist for children, adolescents, and adults within a robust community-wide system.

Studying the multidimensional, dynamic, and complex qualities of a community-wide science education system must begin by creating an expanded definition of what constitutes a public science education system. Rather than conceptualizing the public science education system as schooling alone (pre- $\mathrm{K}, \mathrm{K}-12$, and postsecondary formal education), a system-wide approach recognizes that formal education entities are critical and necessary components but not sufficient; they alone do not constitute the whole system. In a community-wide science education system, the vast array of informal entities such as science centers, digital media, after-school programs, and so on, need also to be included as mounting evidence now shows that these entities equally support the public's science education (Alexander, Entwisle, \& Olson, 2007; Bell et al., 2009; Bøe, 2011; Downey, Von Hippel, \& Broh, 2004; Falk \& Needham, 2011, 2013; Falk, Dierking, Needham, \& Prender- gast, 2014; Lyons et al., 2012; Miller, 2010; OECD, 2012; Ormrod \& Duckworth, 1975; Tai, Qi Liu, Maltese, \& Fan, 2006). Although the formal and informal 
science education institutions in a community have historically been considered as separate systems, they should not be, since there are large overlaps in both audience and espoused goals. This is made clear by recent national science and science education policy statements in numerous countries, including and particularly the United Kingdom, which clearly define specific national priorities related to science education (e.g., HM Treasury, 2004; House of Lords, 2000).

Second, one must identify the specific educational entities in a community and their separate and individual activities, a challenging task in and of itself when taking a community- wide perspective because every community includes many players beyond the most conspicuous entities such as schools, science centers, digital media, and major after-school programs. In addition, one must capture the dynamics of the system. Studying science learning across the entire science education system requires that the researcher analyzes the structure and functioning of the system as a whole, analyzing whether, and if so how, the various entities connect and interact with one another (Maroulis et al., 2010). Finally, there are also temporal implications to this approach. In a world where learning is truly lifelong, and the opportunities for learning, particularly outside of the formal sector, are often cross- generational. In other words, the "beneficiaries" of the system include the learners of all ages, not only children but adults and multigenerational groups such as families as well.

Conceptualizing a community-wide science education system is one thing; identifying the key entities and their activities, and then analyzing the structure and function of the system to determine whether it is healthy and robust, is quite another. By its very definition, a community-wide science education system is complex ${ }^{1}$ as it supports science learning across a range of time frames, learning environments, and configurations, with innumerable possible interactions at the level of individuals, groups, organizations, and institutions. Because system-wide approaches to science education research have rarely been applied, most of the existing research affords researchers, practitioners, and policy makers little, or at best, a superficial understanding of whether, and if so how, the various components of a robust, community-wide science education system might work collectively. Issues related to the alignment of goals between and among providers, leadership, and who important players/stakeholders in the system are, as well as how resources are allocated within the system, are all relevant to understanding how such a system does and could operate. For example, are the myriad science educational entities within the system interconnected in healthy and robust ways that support seamless science learning for all or are they fragmented? Do providers within the system share common goals, are they contributing synergistically to achieving these goals, and are relationships between and among providers reciprocal and supportive? Is the system resilient to disturbance or perturbation? Because system-wide research of this kind is in its infancy in science education, and the theoretical and methodological challenges to taking such approaches are great, it is critical to begin to identify systems to study that are fairly contained and at least theoretically amenable to "management" in support of large, universally agreed upon overarching goals such as the United Kingdom's commitment to achieving widespread public science literacy and engagement (House of Lords, 2000). 
This paper presents exploratory research in which we utilize specific analytical tools and approaches initially developed by community ecologists studying the structure and functioning of biological communities to examine the basic structure and functioning of one particular, fairly contained science education system - the science education system of the United Kingdom. Specifically, we identify the key providers of science education within the United Kingdom, describe their activities, and analyze how these varied science education entities intersect and interact. We examine the U.K. science education system holistically from the top down using a system-wide approach. We assume that this approach will enable a broader, more comprehensive view of the system's strengths and weaknesses offering useful insights into the structure and functioning of science education activities within the United Kingdom, insights that could help researchers, practitioners, and policy makers better understand and ultimately improve the quality of science education efforts there.

1 We use complexity in a very specific way — not "complicated"-but rather characterized by properties and dynamics observed in a wide variety of adaptive biological and social systems (Gell-Man, 1994).

\section{LITERATURE REVIEW Systems Theory}

Systems theory, also referred to as general systems theory, is an interdisciplinary field that studies systems as a whole. Systems theory was founded by William Ross Ashby, a cyberneticist, and Ludwig von Bertalanffy, a biologist, and others between the 1940s and the 1970s, on principles drawn from biology, physics, and engineering (Ashby, 1946, 1947, 1956; von Bertalanffy, 1968). More recently, complex adaptive systems or complexity science have been used as synonyms, thus we will use these terms somewhat interchangeably in this paper.

Complexity science is not a single theory - it encompasses more than one theoretical framework and is highly interdisciplinary, seeking the answers to fundamental questions about living, adaptable, changeable systems. The major tenet of systems theory is that the whole of the system is greater than the sum of its parts. Systems are defined by the dynamic interactions between the parts; these interactions can and do result in the emergence of both affordances and constraints; relationships unpredictable from a knowledge of just the constituent parts (Mason, 2008). Complexity arises in these systems because they are dynamic, self-organizing, and adaptive networks of interactions. Relationships within the system are not aggregations of individual static entities but emerge from individual and collective behavior. External factors, such as time, space, and allocation of resources, also affect the dynamics of complex systems.

Systems theory was developed to understand how relationships and connections between the various sub-elements within the system combine to constitute the whole and how external factors influence the system.

A wide range of disciplines have taken systems approaches to understanding the complex workings of complex assemblages, with the ecological sciences among the earliest of these efforts. Like many fields of biology, community ecology — the study of the 
interactions of the collection of organisms living within a specific geographic areabegan as a descriptive science, but more than a quarter of a century ago, ecologists began applying increasingly sophisticated modeling strategies as a device for organizing systemic complexity and better understanding community dynamics. Since most biological communities are extraordinarily complex, ecologists often focused their investigations of communities on conspicuous, readily identifiable sets of organisms, analyzing the position they occupy in a food chain or other readily measurable relationships between them. This approach enabled ecologists to develop basic understandings of the structure and functioning of the assemblage of key organisms within a community - basically what organisms live there, what activities/roles they play, and what the network of relationships between those organisms looks like. Community ecologists investigate these relationships on a range of spatial and temporal scales, including the distribution, structure, abundance, equitability, and interactions between coexisting populations (Morin, 2011).

Community ecologists discovered that there are some organisms or functional groups of organisms that have a greater impact on the whole than others, whether defined in terms of energy capture, availability of carbon resources, maintaining ecological balance, or some other specific community "goal" (Paine, 1995). As it turns out, frequently these critical organisms or groups of organisms are not the most numerous or conspicuous members of the community, their benefit derives from the critical leverage or, in the case of human systems, the facilitation they support in the system. The ecological term used to describe these important members are "keystone" species or groups (Ripple \& Beschta, 2004; Smith, Peterson, \& Houston, 2003).

Over the past few decades, ecologists have studied how structures and patterns of interaction within a community generate healthier, more robust systems. An interesting finding has been the growing appreciation that independent of the type of community, greater complexity and more integrated and collaborative systems tend to be more productive and more resilient (cf. Levins, 1998; Naeem \& Li, 1997; Tilman, Lehman, \& Thompson, 1997). Concomitant with this finding is that productive and resilient communities support healthy populations of keystone organisms (Ripple \& Beschta, 2004; Steiner, Long, Krumins, \& Morin, 2006). This important quality of robust systems is referred to as coherence. Robust, complex adaptive systems also have reinforcing feedback loops that feed information and resources back into the system. They also often have critical thresholds or tipping points, times at which the behavior of the system changes rapidly due to relatively modest changes in external conditions.

Diversity in a healthy system is more than just the number of species or organizations present in a system (Levins, 1998; Morin, 2011). The key measure for understanding the diversity of a community turns out to be less about individual species and more to do with the assemblages of species, as mentioned earlier, the functional groups of organisms. In particular, it is the organization of the assemblages of species into diverse "niches" (i.e., roles and opportunities organisms or populations take to respond to the distribution of resources and competitors) that actually determines the diversity of a system (Gell-Mann, 1994). Thus an analysis of a community's health and resilience begins with studying the diversity of entities that comprise the community and the ways 
those entities interact and fulfill roles within it, to determine whether the community has "empty niches"-roles, resources, and opportunities not currently being fully utilized (cf. Levins, 1998; Simberloff \& Dayan, 1991).

With recent interest in sustainability, considerable focus of late in systems science has been on the concept of resilience. Although resilience has at times been contested, with critics arguing it is an ambiguous, contradictory term that raises unresolved questions, McAslan (2010) has argued that the differences in definition are not as disparate as some literature may suggest. In general, resilience refers to the ability for a system to absorb and then recover from an abnormal event. Resilient communities are able to cope during such events and recover afterward (Walker \& Salt, 2005).

\section{Applying Systems Theory to Human Communities and Social Science}

Over the past 20 years, community ecology systems approaches have been applied to human communities (e.g., Edwards, 2009; Mahonge, 2010; McAslan, 2010; Socolow, Andrews, Berkhout, \& Thomas, 1994) and used in a wide range of social science disciplines, including healthcare, business management, economics, and public policy (e.g., Brown \& Keast, 2003; Dale, 2003; Hannan \& Freeman, 1989; Hudson, 2004; Klijn \& Koppenjan, 2000; McLeroy, Bibeau, Steckler, \& Glanz, 1988; Winch, 2012).

Just as in biological systems, the resilience of human communities has been found to be dependent on networks of interactions and synergistic actions based on systems of relationships, reciprocity, trust, and social norms (Mahonge, 2010; McAslan, 2010). These networks and interactions in turn are influenced by the underlying diversity of the community (Holland, 2006). Within a human community context, resilience is demonstrated by the willingness and ability of organizations to develop and share common goals and values and to collaboratively respond to change and perturbation (Walker \& Salt, 2005). External factors, such as time, space, and allocation of resources, also affect the dynamics of complex human systems.

Recently, educational researchers and educators have begun to appreciate the potential of this perspective for understanding and facilitating the process of educational change (Jacobson \& Wilensky, 2006). For example, researchers have constructed models to explore the effects of policies that promote school choice in large, urban school districts in the United States (Maroulis et al., 2010), whereas Lemke and Sabelli (2008) advocate taking a systems approach to the planning and design of educational interventions. As they argue, to coordinate effective change in a system, interventions must "actually interconnect actors, practices and events across multiple levels of organization" (Lemke \& Sabelli, 2008, p. 122).

It is important to note that a wide range of social science researchers have borrowed the concept of "ecologies" to frame their research, beginning with Barker and Wright (1951, 1954), Bronfenbrenner's ecological systems theory (1979), ecological psychologists (e.g., Barker, 1968; Falk \& Dierking, 1992; Kaplan \& Kaplan, 1982; Wicker, 1979), and, more recently, learning scientists talking about learning ecologies (e.g., Barron, 2006; Brown, 2000, Jackson, 2013). Although we certainly share the conceptual spirit of these previous 
uses of the term ecologies - the idea that learning is a complex phenomenon that needs to be understood as occurring within the context of a range of sociocultural and physical contexts, multiple factors, and players - this is not our purpose in using this theoretical approach to frame our research. We are directly applying specific analytical tools and system-wide approaches, initially utilized in the field of community ecology (e.g., Falk, 1976; Morin, 2011) and now applied to human systems (e.g., Mahonge, 2010; McAslan, 2010), to describe and analyze the U.K. science education community and its activities as a holistic system, taking a top-down view quite distinct from these other uses of the terminology.

\section{Applying Systems Theory to the U.K. Science Education System}

We began our investigation with the explicit assumption that the United Kingdom possesses myriad science learning resources (both in and out of school). Collectively, these resources represent an educational infrastructure (cf. Bell et al., 2009; St. John \& Perry, 1993), which if successfully accessed and navigated afford rich opportunities for science learning across individuals' days and lifetimes. We also assume that the various providers of science education within the United Kingdom operate as part of a single large, complex system, even if the individual entities within that "system" do not explicitly think of them- selves as being part of a system. We further assumed that conceptualizing and studying a science education community in any country as a system is important because it enables a broader, more comprehensive view of its strengths and weaknesses.

Since we are taking a system-wide approach, we examined the functioning of the whole system, including the relationships between the different entities within the community and their interactions with one another; we did not investigate individual learning experiences or institutions. Thus, our focus was not on how the system supported specific individual learners, but rather on the overall structure of and interrelationships between the major science education entities within the U.K. system. We also were interested in how these entities perceived other entities in the system, for example, did they share common goals and if so how did they build on or leverage what other entities offered to support science learning for all. To study this system in such a way, we needed to develop a basic understanding of the structure and functioning of the assemblage of key entities within the U.K. science education system - in the case of this system, who are the science education providers, what activities/roles do they play, and what does the network of relationships between entities in the system look like (Morin, 2011). Important to note is that although we can characterize science education within the United Kingdom as a discrete entity, all communities are parts of both a larger systemthe ecosystem in which they are embedded - as well as interconnected with other nearby communities. $^{2}$

\section{Structure of the U.K. Science Education System: Identifying the Entities}

While we could have approached this task without any initial assumptions about the identity of the major science education entities in the current U.K. science education system, we knew establishing the evidence and criteria for what constituted a "major" 
provider of science education would have been a study in itself. Instead based upon prior investigations primarily conducted in the United States (Bell et al., 2009; Falk \& Needham, 2013; Falk, Randol, \& Dierking, 2012), we began with the a priori assumption that U.K. science education entities could be reasonably grouped into a finite number of sectors. Much as a community ecologist might group the numerous organisms within a community into a finite number of functional assemblages (e.g., primary producers, canopy herbivores, insectivores, carnivores, and scavengers), representing species with similar roles - we identified assemblages of science education entities and placed them into functional sectors. Collectively then, each sector offers up a range of educational offerings to some group of learners, i.e., audiences, to accomplish a range of educational outcomes, e.g., goals, which collectively define the "niche" of the sector. Accordingly, we assumed that entities within a sector were likely to target similar audiences (e.g., science centers target families and school groups with primary school-aged children) and have similar goals (e.g., broadcast media promote interest and curiosity), though of course considerable overlap in both audience and goals between sectors was likely.

One other characteristic of our system-wide approach to describing the system is important to note. Unlike many previous "system-wide" studies (e.g., the various Eurydice reports describing national European education systems ${ }^{3}$ ), we did not begin with the assumption that the focal point of the U.K. science education system was schools. As described earlier, a growing literature supports the critical role that informal science resources contribute to public science learning, particularly when one takes a lifelong, life-wide, and life-deep view. Thus, we begin our investigation with the view that the various science education sectors are equally important to the public's science learning, that is, each is assumed to have equal stature within the system.

In summary, based on this review, our three framing assumptions are as follows: (1) science learning resources in the United Kingdom are organized into a complex system, (2) the public's science learning is supported by a finite number of science entities organized into "sectors," and (3) each sector has a niche defined as the menu of science education experiences it offers to specific audiences to achieve specific science education goals. To the extent possible, our goal was to provide a "bird's-eye view" of the entire U.K. science education system, by describing and analyzing the relative contributions and interrelation- ships between and among the various science education sectors in the system (e.g., science centers, schools, youth groups, forums, media).

${ }^{2}$ The U.K. science education community is embedded within a series of much larger United Kingdom and European geographic, historical, political, and social systems. It also interfaces with other communities such as the U.K. arts and cultural education community and the U.K. leisure and tourism community, as well as the occasional involvement of other professionals such as university researchers or software developers. These relationships, though obviously important, were beyond the scope of this initial investigation.

3 cf. https://webgate.ec.europa.eu/fpfis/mwikis/eurydice/index.php?title=Home. 


\section{Research Goals and Questions}

Using the United Kingdom as a case study, we use specific analytical tools and systemwide approaches from the field of community ecology to describe and analyze the U.K. science education community and its activities as a holistic system-viewing it from the top down as a community ecologist might study any complex biological community. We provide a first-order understanding of the structure and functioning of this system, including the types of activities provided and unique mixes of audiences they served within a specific geographical area.

Ecologically speaking, robust and healthy systems are resilient, supporting diverse functions, and critical, i.e., keystone species. Since research also suggests that healthy human communities are dependent on social interaction and collective action based on networks of relationships, reciprocity, trust, and social norms, we also focused on these properties of the system.

Our research questions were as follows:

1. What collectively, are the science education niches supported by the current U.K. science education system-audiences served and goals aspired to?

2. How do science education entities perceive their position within the entire U.K. system? Specifically, is there appreciation for the contributions and interrelationships of all parts of the system or does there appear to be sectorspecific myopia?

3. What is the relationship between and among sectors? Are there discontinuities or gaps that prevent the system from functioning holistically and synergistically?

Ultimately, our research goal was to determine to what degree educational entities within the U.K. science education system are currently interconnected in healthy and robust ways that optimally support seamless lifelong science learning for all.

\section{METHODS}

As far as we know, a study of this nature has not been attempted before. First and foremost therefore, it is an exploratory study to describe the major features of the science education system in the United Kingdom, essentially a first-order view of the system.

\section{Identifying Sectors}

As described earlier, based upon research conducted in the United States (Bell et al., 2009; Falk \& Needham, 2013; Falk et al., 2012), the science education resources of the United Kingdom were organized into distinct science education sectors. Although we could have started with large groupings such as "designed spaces," "media," and "programs" (Bell et al., 2009), the public, as well as those who work within these settings, distinguish between entities based upon their differing goals and physical contexts. As a consequence, we came up with 16 discrete sectors plus a 17th "other" 
category (Table 1).

\section{Research Instrument}

We sought to answer our research questions by sampling key science educators from across the entire U.K. science community. Because individuals in our study represented quite different sectors scattered around the United Kingdom, the instrument was administered via the Web. The study questionnaire was developed through an iterative process. Based on analysis of an initial series of semistructured interviews $(n=51)$ of U.K. science education providers representative of the 16 identified sectors along

TABLE 1: Sector Categories and Usable Survey Responses by Sector

\begin{tabular}{|c|c|c|}
\hline Organization Type & Number & $\begin{array}{l}\text { Percentage of } \\
\text { Respondents }\end{array}$ \\
\hline $\begin{array}{l}\text { Education (a science organization or } \\
\text { business primarily focusing on educational } \\
\text { enrichment, e.g., Do Science, Ltd.; Hands } \\
\text { on Science, Ltd., and Mad Science East } \\
\text { Midlands) }\end{array}$ & 36 & 18.0 \\
\hline School (both primary and secondary) & 27 & 13.5 \\
\hline $\begin{array}{l}\text { Science center (science and discovery } \\
\text { center) }\end{array}$ & 26 & 13.0 \\
\hline $\begin{array}{l}\text { Museum (e.g., natural history museum, } \\
\text { science and industry museum) }\end{array}$ & 24 & 12.0 \\
\hline $\begin{array}{l}\text { Org.: Not education (a science organization } \\
\text { or business where educational enrichment } \\
\text { is not the main business, e.g., science } \\
\text { research organizations, health } \\
\text { organizations, technology company) }\end{array}$ & 23 & 11.5 \\
\hline $\begin{array}{l}\text { Broadcaster (e.g., TV, film, or other media } \\
\text { producers) }\end{array}$ & 14 & 7.0 \\
\hline $\begin{array}{l}\text { Learned society (e.g., Royal Society of } \\
\text { Chemistry, British Medical Association) }\end{array}$ & 12 & 6.0 \\
\hline University & 11 & 5.5 \\
\hline $\begin{array}{l}\text { Electronic media (e.g., Web sites, games, } \\
\text { videos) }\end{array}$ & 6 & 3.0 \\
\hline Zoo/aquarium & 6 & 3.0 \\
\hline Science festival & 4 & 2.0 \\
\hline $\begin{array}{l}\text { Hobby club (also community groups or sports } \\
\text { clubs) }\end{array}$ & 3 & 1.5 \\
\hline Nature center (also parks or field centers) & 1 & 0.5 \\
\hline Theater group & 1 & 0.5 \\
\hline Library & 1 & 0.5 \\
\hline $\begin{array}{l}\text { Publisher (of printed science books and } \\
\text { magazines) }\end{array}$ & 0 & 0.0 \\
\hline $\begin{array}{l}\text { Other (any respondent who felt his or her } \\
\text { organization did not fit one of the above } \\
\text { categories) }\end{array}$ & 5 & 2.5 \\
\hline Grand total & 200 & 100.0 \\
\hline
\end{tabular}


with an accompanying literature review of the field (cf. Falk et al., 2012), an initial set of questions were developed by the members of the research team and carefully narrowed down to reflect the primary objectives of the research project. This process resulted in 28 questions carefully worded to reflect the U.K. cultural and educational context. These questions were then vetted by the larger research team and subsequently coded into an online questionnaire for testing. Research participants were asked to respond not as individuals per se, but as representatives of their organizations. The questionnaire was piloted by a small group of stakeholders, and this group's feedback on the content and wording of items, their ability to reflect upon their organization's goals/roles, and the implementation of the questionnaire on the Web site, were used to refine the instrument and its administration (cf. Falk et al., 2012). It should be noted that the full instrument was designed to fulfil a number of research goals; only roughly one third of the instrument's questions specifically related to the goals of the research reported in this paper (see the Appendix for the specific questions used in this study). Based on the testing, the full questionnaire required 20-30 minutes to complete.

An initial sample of 326 science educators (inclusive of university science education faculty but exclusive of individuals from primary and secondary schools) was identified from a variety of sources and sent the questionnaire. This list was assembled from contacts provided by the funder of the study, members of the science directories, the U.K. Associ- ation of Science and Discovery Centers, U.K. science education Listservs, ${ }^{4}$ and addresses collected from entities Web sites. All targeted individuals were senior individuals within their respective organizations so as to be capable of reflecting an institutional perspective. A wide variety of distribution lists were selected to maximize coverage — both categori- cally and geographically — and allow for a range of organizational participation. Additional organizations and specific individual contacts were suggested by interview participants. A second round of recruitment e-mails was sent to an additional 40 organizations and individ- uals directly; a total of 366 surveys in all were distributed. It was never assumed that this survey of U.K. science education entities would represent a random sampling of the entire U.K. science education community. The goal was to include as broad and representative a sampling of the identified sectors, by geographic distribution, type of organization, sizes, and activities, from across the entire United Kingdom as possible.

After the initial round of surveys was completed, a "short" version of the questionnaire was created which only included the subset of questions directly relevant to study findings presented in this paper. Two additional populations were sent this shortened version of the instrument. The first were administrators and coordinators of school (both primary and secondary) science programs. Participants were recruited primarily by e-mail sent to Listservs for science program coordinators in physics, biology, and chemistry. This questionnaire was also administered online. A second similarly streamlined version of the questionnaire was also targeted at sectors for which there was a low response rate from the initial longer instrument. Sectors targeted for this version of the questionnaire included libraries, hobby and community groups, broadcasters, nature centers and parks, publishers, science festivals, and theater groups; this version too was administered online and advertised through fliers at project-related events. Final responses were 
geographically, broadly representative of the United Kingdom (Table 2).

\section{Analytical Framework}

Survey data were analyzed utilizing a series of community ecology-style approaches. The following features of the community were examined:

1. A niche analysis that explored the range of audiences served and goals espoused. Audience. We analyzed the data to determine how the different sectors/groupings individually and collectively serve the U.K. public. From a predefined set of cate- gories, individuals were asked to indicate their primary and secondary audience(s) based upon a course-grained set of five predefined age categories emphasizing, per the wishes of the funder, children, and youth. Just as organisms within a biological community may not efficiently be taking advantage of all available resources, so too may audiences may not be fully accessing the science education resources of an educational community.

TABLE 2: Usable Survey Responses by Region and in Comparison With Actual Population (2011 U.K. Census)

\section{Usable Survey Responses by Region and in Comparison With Actual Popu- lation (2011 U.K. Census)}

\begin{tabular}{lccc}
\hline Location & Number & Percentage & Actual Percentage \\
\hline North East & 16 & 8 & 4 \\
North West & 18 & 9 & 11 \\
Yorkshire and the Humber & 4 & 2 & 8 \\
East Midlands & 10 & 5 & 6 \\
West Midlands & 14 & 7 & 9 \\
East of England & 3 & 1.5 & 9 \\
London & 57 & 28.5 & 15 \\
South East & 10 & 5 & 13 \\
South West & 29 & 14.5 & 9 \\
Scotland & 11 & 5.5 & 8 \\
Wales & 8 & 4 & 5 \\
N. Ireland & 5 & 2.5 & 3 \\
Virtual & 8 & 4 & - \\
Unknown & 7 & 3.5 & - \\
Grand total & 200 & 100.0 & 100.0 \\
\hline
\end{tabular}

And, although it might be assumed that a mature science education community such as the one in the United Kingdom should collectively be serving the needs of all citizens, perhaps it is not.

Educational Goals. Another dimension of niche is the key educational outcomes or goals of each sector so we analyzed community education goals based on the rank-ordering respondents gave for of their institution's/sectors goals from a prede- termined list of educational outcomes provided on the questionnaire. 
2. A sector interaction analysis, the next level of analysis, explored the kinds of relationships that existed within and between sectors, such as which sectors were deemed as important within the U.K. science education system, which kinds of sectors collaborated with one another (or not), which overlapped, which competed, and whether one group was "used" by another. This analysis focused on research participants' rating of each of the 17 sectors in terms of its relative importance to science education overall in the United Kingdom. How each of the sectors interacted within the community/system as a whole, what interrelationships existed, and were the relation- ships between sectors reciprocal and mutually beneficial (e.g., symbiotic) or more one sided (e.g., commensal or parasitic)?

3. A sector interdependence analysis that explored the perceived degree of interaction, reliance, independence, and cooperation between sectors and the "flow" of those interactions, since from an ecological perspective the importance of any particular constituent of the community is not determined exclusively by its abundance or size but equally by its level of interactivity and interdependence within the system. In other words, which sectors seemed to play a vital role in regulating the flow and well-being of the system as a whole? This analysis focused on research participants' ratings of their interactions with members of their own sector, as well as their interactions with all other sectors.

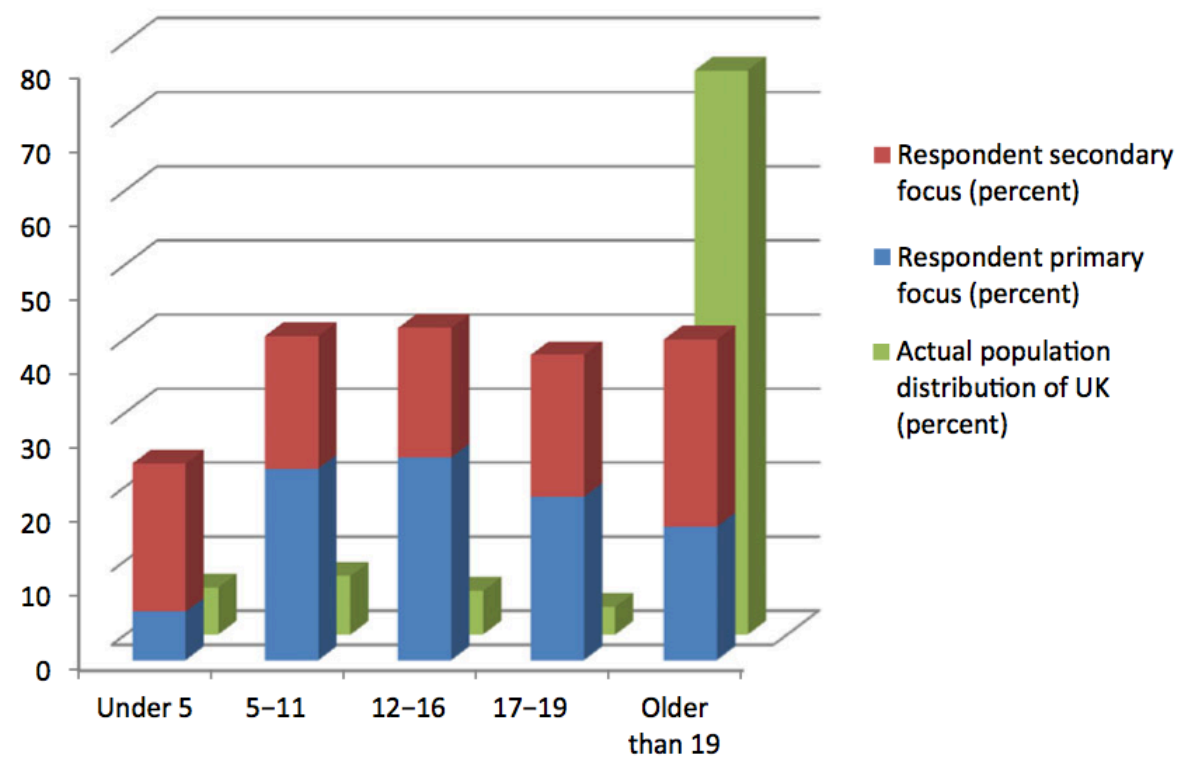

Figure 1. Chart comparing the distribution of the total U.K. population by age group with the percentage distribution of audiences said to be served by the respondents to the survey.

${ }^{4}$ More general recruiting was done through Listservs run by the British Interactive Group, the Visitor's Studies Group, the public communication of science Web site (pscicom), which is used by many individuals working in universities, and the list within the National Academic Mailing Service and the Group for Education in Museums. 


\section{RESULTS}

The initial administration of the survey generated 196 completed responses; 169 had sufficient data to be included in the analysis (initial response rate of $46 \%$ ). As described in the Methods section, two additional "short" versions of the questionnaire were administered to try to increase the response rate, one to administrators and coordinators of school science programs, which resulted in an additional 21 responses, and the other targeted at libraries, hobby and community groups, broadcasters, nature centers and parks, publishers, science festivals, and theater groups. Ten additional surveys were completed, all from a single sector-broadcasters. In total, the $n$ for completed, analyzed surveys was 200 (final response rate of 55\%). In all survey rounds, no attempt was made to restrict responses to one individual per organization, as the intention was to collect views from as broad a range of senior individuals as possible; all final comparisons between sectors were normalized so that the "weight" of each sector was equivalent, regardless of the number of responses received from that sector. Responses by organization type are included in Table 1.

\section{Niche Analysis}

Audiences Served. An initial analysis of audiences served by sector was conducted. With the exception of the obvious distinctions (e.g., schools were more focused on schoolaged children than adults), little variability in distribution of audiences was found across sectors. At least one representative from each sector indicated that they attempted to serve each audience segment. It was only at the level of the whole community that a reasonable distribution of priorities could be discerned. Figure 1 shows the collective audience priorities, by age group, of the U.K. science education community as compared to the relative numbers of these same age groups within the United Kingdom. ${ }^{5}$ Two things clearly emerge in Figure 1. The first is that every age group is a priority of someone within the science education community. The second is that educator priorities are not perfectly matched to population with a decided bias toward children and youth.

${ }^{5}$ Family groups were an important audience for many groups in the survey, and this audience obviously includes both adults and children, particularly younger children. However, these data were excluded from Figure 1 for lack of ability to know how to accurately apportion the data. That said, including these data would likely not have significantly changed the basic observed patterns. Data from the United States, for example, show that the majority of family visits to informal venues disproportionately include children between the ages of 5 and12 (Falk \& Dierking, 2013). Other data, also from the United States, find that a majority of the adults on these family visits focus almost exclusively on their child's experience rather than their own science learning (Falk \& Needham, 2011). Thus, even if we had included these family visit data in Figure 1 , it would not have appreciably changed the distribution of science education resources in the United Kingdom, which appear to serve school-aged children rather than adults. 
Although our survey data did not permit a comparable analysis as a function of urban versus rural, or "privilege," as defined by socioeconomic status (SES), our hypothesis, supported by the U.K. government's "Taking Part" survey (Department for Culture Media and Sport [DCMS], 2011), is that a similar reality exists for these two dimensions as well- namely that the public within metropolitan areas have proportionately more opportunities for community-wide science learning than the public in rural communities (again, it is important to note that the measures reported here do not account for the quality of these opportunities, only their quantity). Similarly, there is evidence that individuals from higher SES groups are more adequately focused on than are those from lower SES groups (Dawson, 2012).

Education Goals. Each research participant was asked to rank order their institution's goals. As above, there was very little intersector variability. In fact, all participants, including schools, converged on just a few primary educational outcomes - "make science enjoyable and interesting" (91\%) and "inspire a general interest in and engagement with science" (89\%). The least supported outcomes for all sectors, including schools, were "prepare participants for future science education or careers" $(27 \%)$, "encourage further learning in nonscience subjects" $(23 \%)$, and "prepare participants for nonscience careers" (e.g., skills development) $(12 \%)$.

\section{Sector Interaction Analysis}

In examining the structures and relationships of the various sectors within the U.K. science education community, one of the important questions that emerged was whether any of the various sectors seemed particularly important to the functioning of the system, that is, could we identify which, if any, sectors potentially function like keystone groups? Survey participants were asked to rate each of the 17 sectors on its relative importance to science education overall in the United Kingdom. Figures $2 a-2 c$ show the normalized 6 responses to the question of "who's important?" from the perspective of 3 of the 17 sectors - science and discovery centers, universities, and learned societies; together these three

${ }^{6}$ By normalized, we mean that a mean response from each of the 17 sectors was utilized - responses varied from +9 (total agreement by all responding that this sector was one of the three most influential) to -9 (total agreement by all responding that this sector was one of the three least influential). The actual bars on the graph represent the overall "score" each sector received, displayed as a percentage (in this case "normalized" essentially means "averaged"). The error "bars" or "markers" indicate whether there was disagreement between those responding about whether they believe the sector to be one of the three "most important" (receiving a score of +1 ), or one of the three "least important" (receiving a score of -1 ). If the sector was not chosen as one of the most or least important, it received a score of zero (0). If no disagreement markers are present, that means there was agreement among those responding, who either left it blank (marked as 0$)$ or rated it the same $(+1$ or -1$)$. 


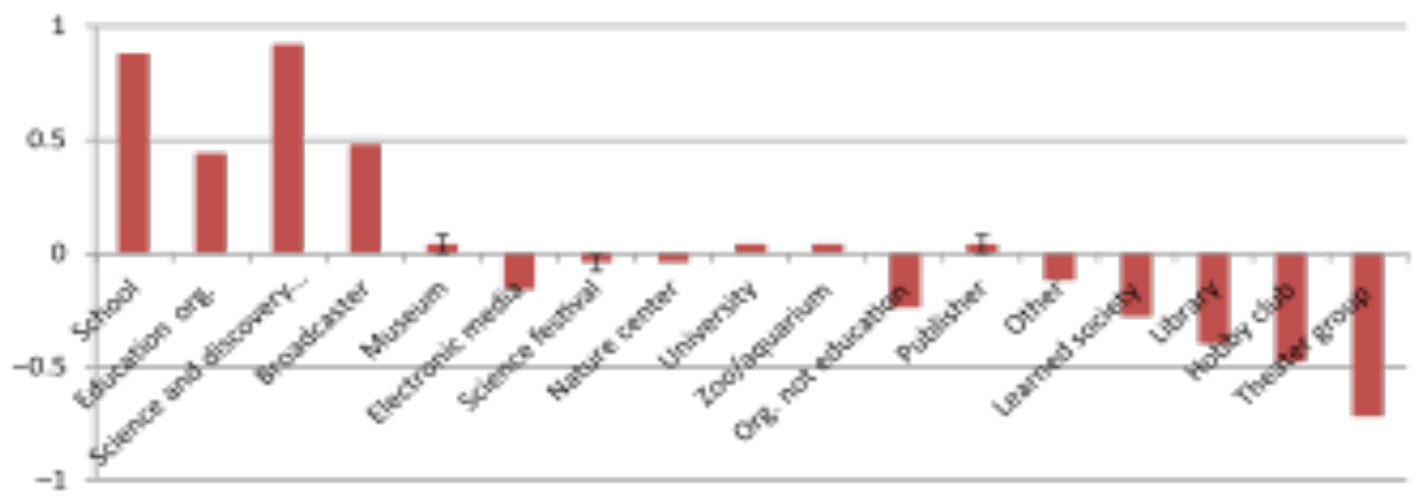

[a]

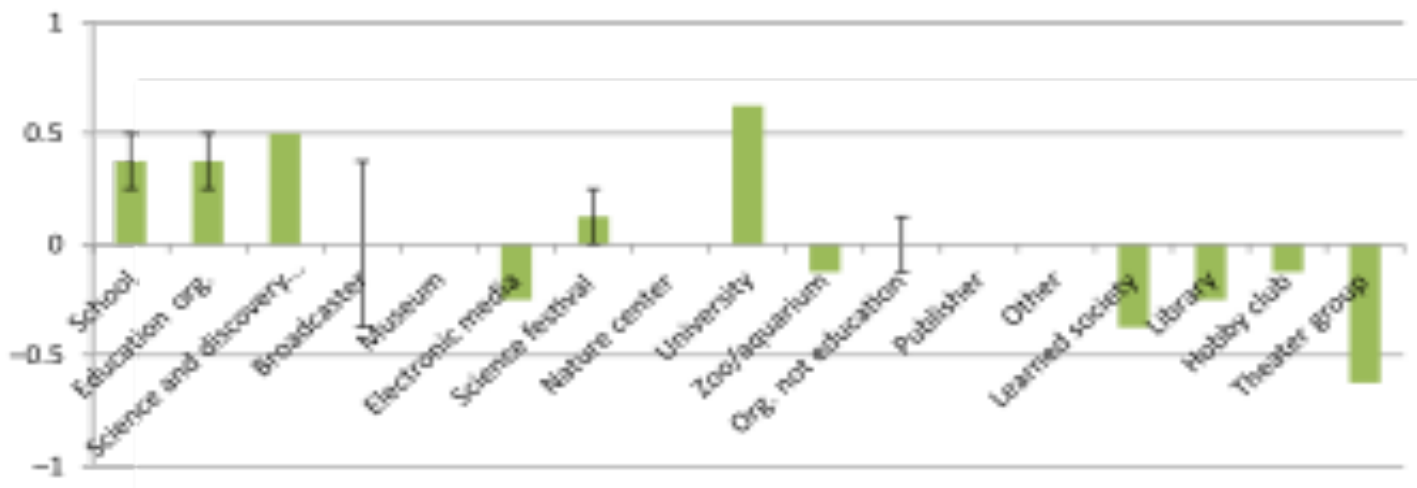

(b)

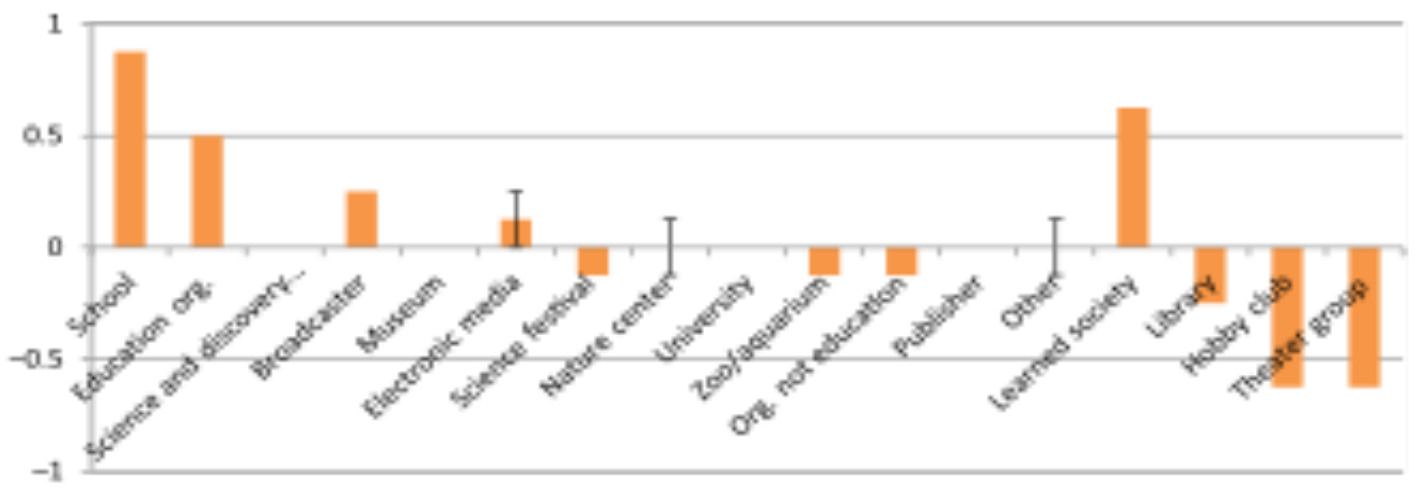

(c)

Figure 2. Normalized survey rankings to the question: "Who's most important .. . " for different sectors: (a) science and discovery center, (b) university, and (c) learned society. examples reveal the basic trend seen in all responses. The "error bars" in the figure actually represent "agreement-disagreement bars"; the amount of concurrence within the 
sector on whether another sector was important or not. Sometimes no disagreements occurred - all respondents agreed a sector was important or unimportant - these are the cases where no "bars" appear.

Although there are some similarities in rankings between Figures $2 \mathrm{a}, 2 \mathrm{~b}$, and $2 \mathrm{c}$, there are also stark differences. In general, all groups seemed to agree that schools are important, as are organizations that provide science engagement and enhancement activities as their primary focus (Education Org.). Also frequently mentioned as important were science and discovery centers and broadcasters. Other than schools, the only clear pattern across various sectors was that, on average, respondents within each sector had a much higher opinion of the importance of their own sector than did the average represented by all groups.

Sector Interdependence. We explored the perceived degree of interaction, reliance, independence, and cooperation between sectors and the "flow" of those interactions. Our data suggest that schools are highly utilized by many, if not most, members of the science education community in the United Kingdom. We wondered though whether these interactions are multidimensional or only one way. We know that many informal organizations interact with schools for primarily structural reasons, driven by a desire to gain access to school-aged children, since the vast majority of children between the ages of roughly 5 and 18 years attend school. The question that emerged was whether schools as well as the other conspicuous sectors such as broadcast media, science centers, and science education organizations function more like highly visible but ecologically isolated islands of resource or do they serve as dynamic hubs, supplying multiple, reciprocal benefits and resources for the U.K. science education community. Ecologically speaking, another way to frame the question of importance then is to determine which sectors play a vital role in regulating the flow and well-being of the system as a whole. With this in mind, in addition to being asked about who they thought was important, survey participants were also asked to rate their interactions with members of their own sector, as well as their interactions with all of the other sectors. The results of our analysis were as follows:

- All sectors, except schools, reported frequently collaborating with other organizations within their own sector (mean score of 3.78 out of 4 with a variance of 0.05 ).

- Compared to other sectors, schools reported collaborating less frequently with each other (2.62 out of 4 , variance of 0.33$)$.

- Overall, collaborations across the sectors in the sample had a mean score of 2.94 out of 4 (variance of 0.42 ).

- Nearly all informal sectors reported working/collaborating with schools. In contrast, schools reported only occasionally and only weakly working/collaborating with in- formal organizations. The data suggest that overall, with the possible exception of schools, the U.K. science education community is highly interconnected. At least among the individual organizations and sectors sampled, 
all are highly mutualistic within their own group and moderately mutualistic with collections of organizations beyond their own sector. The major outlier to this generalization was the schools sector and to a lesser degree universities. The twodozen schools in our sample acknowledged that they were the recipients of considerable attention from others, but they did not seem to initiate collaboration actively with anyone else, including other schools. We attempt to depict these interactions in two different ways. Figure 3 is a traditional network map based on the quantity of interactions existing between each of the various sectors. This map was created by inserting the quantity of reported interactions between sectors into the open-source visualization software, Gephi (Bastian et al., 2009). The greater the quantity of interactions and the greater the number of other sectors interacted with the closer an organization is to the center of the figure. The sectors in the center of Figure 4 have the highest rates of interconnectivity, followed by those in the next ring out, and so on, with the least interconnecting sectors in the outer ring.

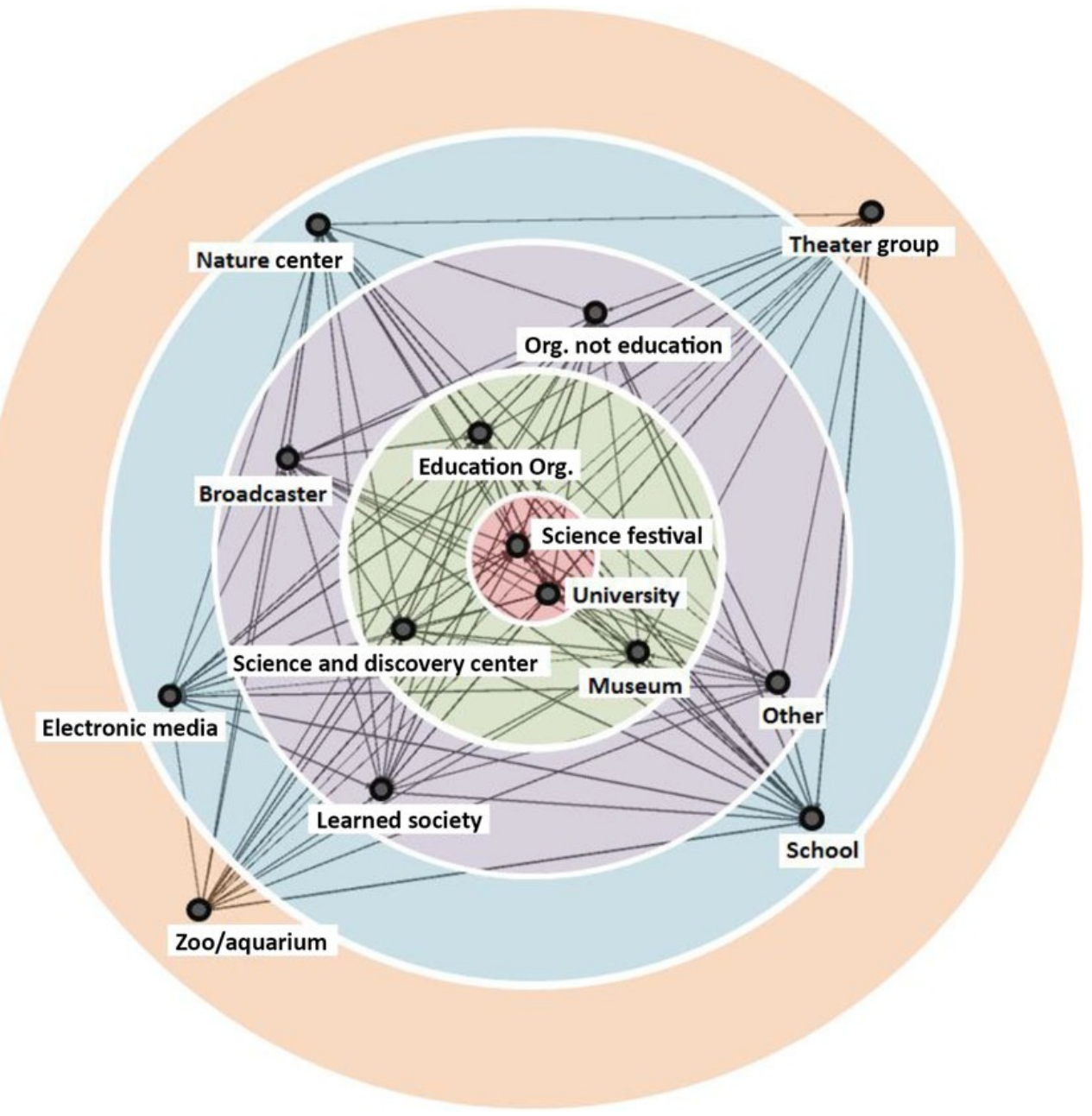

Figure 3. Reciprocal interactions among U.K. science education sectors: greatest interactivity in the middle. 
Those sectors closest to the center of the diagram are, in theory, the most integrated and interconnected sectors in the community and those in the outer circles the most peripheral. Looking at the community from this interactional perspective, schools emerged as one of the more peripheral sectors, while science festivals and universities appeared to be very much at the hub. ${ }^{7}$ Also highly interconnected with the broader community were science and discovery centers, museums, and organizations that provide science, technology, en- gineering, and mathematics (STEM) engagement and enhancement activities. It is worth noting that there was little correlation between the position of an organization in Figure 3

and the individual sector ratings of "importance" as shown in Figures $2 a-2 c$. The analysis shown in Figure 3 provides an interesting but somewhat exaggerated view of the interconnections within the U.K. science education community. Although Figure 3 would suggest that all of the sectors are highly integrated and interconnected, the reality was more complex and nuanced. Figure 3 was a composite of all responses within a sector, thus, if even one organization within a sector said it connected with another sector, it was counted as a connection between sectors. As a consequence, Figure 3 overstates actual between sector interactivity. In other words, the fact that in Figure 3 universities,

${ }^{7}$ One reason universities may appear at the center of Figure 4 could be because of the recent Research Councils U.K. Beacons of Public Engagement initiative, which has fostered an increased role for select universities within the science learning and engagement community. Given the snapshot nature of our current data, we have no way of determining whether the current position of universities is a short-term aberration or a more permanent fixture of the community. 


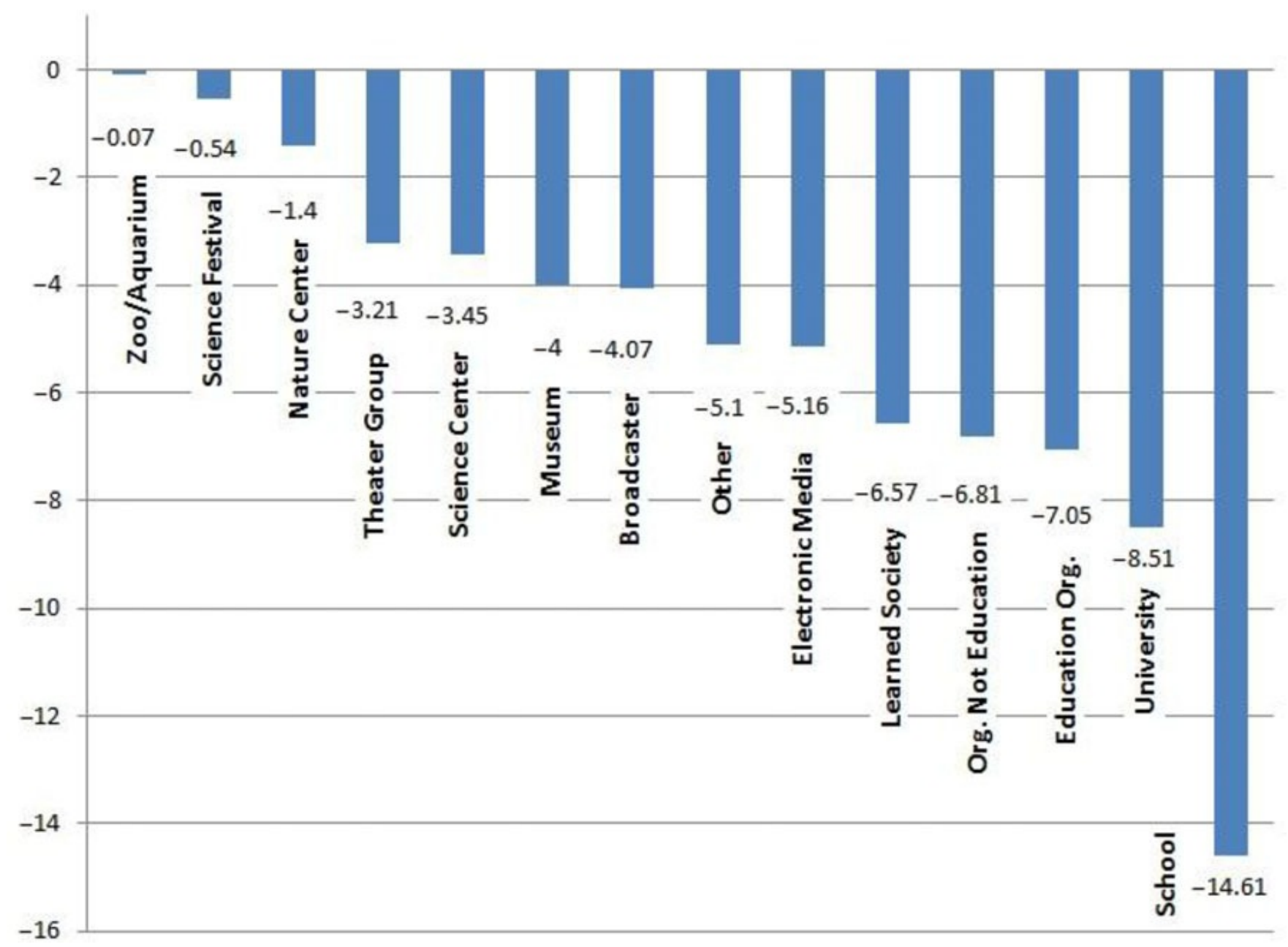

Figure 4. Unreciprocated flow of interaction/attention within the U.K. science education community ( 0 on the $y$ axis represents equal reciprocation with others, a negative number an imbalance of reciprocation toward the institution labeled).

for example, are shown as quite central (in that they have connections with virtually all other sectors) only means that collectively across all of the universities sampled, at least one university had a connection with each of the sectors. It fact, when responses from just within the university sector were analyzed, there was extreme variability. A couple of university respondents indicated strong and frequent interactions with other sectors, but most university respondents indicated that they interacted infrequently and then only weakly with other sectors. This was generally true of all sectors with the exception of three - science and discovery centers, museums, and science festivals. Within these three sectors, all respondents indicated high levels of consistent and strong interconnectivity.

One final way of measuring community interaction is shown in Figure 4. Figure 4 focuses on the issue of reciprocity and shows the level of shared interactions that occurred between different sectors. Each survey respondent was asked to rate how frequently he or she interacted with other sectors as well as how frequently other sectors interacted with them. A score near zero indicates that organizations within this sector 
give about as much attention as they receive (i.e., complete reciprocity), whereas a larger negative score indicates that organizations within this sector receive more attention than they give (i.e., one-sided interactions). To the left within Figure 4 are groups such as science festivals and zoos and aquariums which appear to be highly reciprocal (or have a minimum of unreciprocated interactions) with others in the system. That is, the score allocated for the number of providers they said they worked with differed little from the score given for the number of people who said they worked with them. Also toward this end of the scale are nature centers, parks, and field centers. As we move farther to the right in the figure, the imbalance of interaction increases. The university and school sectors are at the far end of the continuum; each receiving considerably more attention from others than they give back in return.

As stated earlier, a complete understanding of the current web of interactions within the U.K. science education community requires combining understandings that result from the relationships shown in Figures 3 and 4; collectively, these enable us to view both connectedness and reciprocity. From this perspective, three sectors appear to emerge as deeply intertwined in the fabric of U.K. science education and thus might potentially represent, from an ecological perspective, keystone sectors that are important to the health of the community-science festivals, science centers, and science museums. Confirming this deduction, though, will require further testing.

\section{DISCUSSION}

The primary goal of this research was to begin the process of conceptualizing the science education community of the United Kingdom as a complex whole. Our preliminary scan of the U.K. science education system only begins to scratch the surface of how to define and conceptualize it as a system. And despite the limitations of our sampling that undoubtedly influenced results, several important findings emerged.

First with regard to niche, our initial assumption that each sector would have a clearly defined niche as defined by audience and goals was not borne out by the data. There was significant convergence in goals by all members of the science education community around promotion of science interest and engagement and convergence on school-aged children as a focus. These findings have several implications. First, it confirms our assumption that this is a single system. However, with regard to our methods, it suggests either our construct of niche was insufficiently fine grained to distinguish between sectors or that our definition of sectors was fine but that organizations that make up these sectors possess insufficiently focused priorities - in terms of both audience and goals. Either way, the current situation suggests that the system as a whole is not optimally functioning since, in general, everyone in the system appears to be trying to accomplish much the same thing for many of the same people while leaving other audiences and goals relatively unattended to. For example, although it is generally assumed that primary school-aged audiences are a major focus of the nonschool community, this analysis suggests otherwise. Interesting too is that the demographic of 17-19-year-old youth that many claim to be "hard to reach" is, at least as a function of sector priorities relative to their numbers in the overall population, being proportionately served (perhaps with limited success, but seemingly not for lack of trying). 
By this analysis, the adult age cohort is the most underrepresented priority of the U.K. science education community. Similarly, little community-wide attention is being directed to arguably the important goal of preparing individuals for future science-related careers. On the positive side, this convergence in preferred outcomes by all sectors could be a foundation for facilitating and encouraging greater collaboration among and between sectors across the community.

Our results do throw into question the current practice of characterizing the science education community dichotomously as either "formal" or "informal." Currently within the community, there are many providers of science educational experiences, many with seemingly similar goals and target audiences, some of which are formal and some which are informal, and some whose efforts cut across the formal-informal dichotomy. Hence, the artificial distinction between formal and informal learning appears to be ultimately unhelpful.

With regard to interactions, our initial analysis suggests that there is a high degree of interactivity within the greater U.K. science education community, but in general collaboration and by extension, meaningful synergies are quite patchy and episodic. Some organizations within each sector have connections to other sectors, but most entities within these sectors lack long-term and well-distributed collaborations. In general, a high degree of ego-centrism and myopia was observed within each of the sectors, with each sector having a somewhat overinflated sense of its own value and importance, by and large primarily valuing only those most closely connected to their own needs and priorities. Lacking was a sense of the United Kingdom as whole, interdependent system with each of the sectors contributing something important. Schools in particular and universities, to a lesser degree, emerged as highly exploitive, dare we suggest parasitic. Virtually, all sectors in some way or another catered to the needs of schools but received little service in return. This was true even among entities within the school sector. Data showed that schools do not regularly collaborate with other schools either. By contrast, organizations such as science centers, museums, and science festivals emerged as the most highly collaborative and interconnected. Whether this qualifies the latter three sectors as candidates for the designation of "keystone sectors" is probably premature.

Our analysis of community organization was based on the assumption that there were 17 major types of science education sectors in the United Kingdom. Although this framing assumption allowed us to develop some initial insights into the structure and functioning of the community, the need for a more fine-grained analysis is apparent. Although this initial analysis provided some intriguing hints as to relative contributions of these various sectors, ultimately it was impossible to demonstrate the importance of any particular sector or group of sectors and its contribution in the absence of additional data. Of particular importance would be a study that begins with an effort to develop meaningful groupings of similar entities using multiple data points; in other words, a true niche analysis. However, even based on this exploratory and coarse-grained analysis, we can say some things about the diversity and resilience of the current U.K. science education system.

\section{Diversity}


The generation and maintenance of diversity is fundamental to healthy systems because greater diversity leads to greater complexity (Gell-Mann, 1994). The essential challenge, though, is to understand what sustains diversity at the level of the overall community. It is often assumed that diversity simply represents the number of entities present. However, as we saw in our analysis of the U.K. science education community, our understanding of the complexity of the community primarily emerged as we investigated diverse ways in which the sectors interacted within the community. That said, it is fair to say that the U.K. science education community has been considerably enriched by the increase and diversification of out-of-school science education providers in the past few decades, which have added considerably to the quantity and presumably quality of interactions. Notably, even using our admittedly crude division of the community into 17 sectors, the vast majority of sectors, and hence interactions, were out of school. Inferential data from the United States suggest that increasing diversification of science education resources can directly lead to improvements in public science literacy (Falk \& Dierking, 2010; Falk \& Needham, 2013).

Nevertheless, despite the maturity and complexity of the U.K. science education community, our study identified gaps in service. Currently, there appears to be an abundance of effort focused on serving the school-aged population, but arguably insufficient priority given to adults and children under five. There are also presumed inequalities in resources available to urban and rural communities and individuals from lower socioeconomic conditions. Such gaps in the distribution of niches/resources are to be expected. As occurs regularly in both biological and human communities, niche/resource distribution patterns typically are a result of some combination of history and opportunity. That said, it seems that filling these gaps should be an important priority for the community. Though there are clearly things that individual organizations and sectors can do to ameliorate these issues, it cannot reasonably be seen as the sole responsibility of any one organization or group of organizations. Our view is that some kind of whole-system perspective would be beneficial. Given the complexity and current political realities of the U.K. science education community, this kind of systems management will require that the views, values, and interests of both "top-down" stakeholders, e.g., government, private funders, as well as "bottom-up" stakeholders, e.g., key representatives from the delivery side of the system are included. Although there is no shortage of goodwill, creating the necessary incentives to insure that all citizens are supported, regardless of economic or social means, is unlikely to just hap- pen, despite, for example, the current efforts by many members of the science education community to specifically target disadvantaged communities (DCMS, 2011).

\section{Resilience}

Superficially, the U.K. science education system is a highly interconnected and interdependent system, which by definition would make it highly resilient. However, a more fine-grained view of the system suggests that there are significant distortions in the system with some very large entities, in particular schools and universities, disproportionately dominating at the expense of the other sectors. Normally, the development of patterns of interconnectivity and interdependence are both a natural consequence of the self-organization of any complex system and an essential element in 
the robustness and resilience of the community; however, historical and/or external factors can override these self-organizing principles. For more than a century, schools and universities have been afforded primacy within the educational community. As an outgrowth of this history, reinforced by statutes, schools and universities have not had to compete for resources to the same degree as other sectors within the community and thus have effectively distorted the community that sup- ports the learning of science. As discussed in the Introduction, schooling provides only a portion of a society's science learning opportunities. As we move into the 21 st century, it makes increasing sense to reconsider how resources are allocated across the community; allowing all facets of the science education community an equal opportunity to thrive based upon their capacities and capabilities. Potential candidates for additional support might be those organizations/sectors that truly function in a keystone capacity. Although historically it was assumed that schools play this keystone role, our findings suggest that if you look systemically sectors such as science festivals, science centers, and museums might actually be playing these roles. Clearly, additional investigation will be necessary to confirm this hypothesis. Regardless of which entities emerge as keystone organizations/sectors, the reason for supporting these keystone groups disproportionately is that they have the potential to add significant value to all players in the community by virtue of their interconnectedness and community-wide collaborations, which support synergies and in so doing, increase overall capacity.

A major policy question then is how would management of science education within the United Kingdom be different if policy makers and funders took a more systemic perspective? What aspects of the system would be most amenable to this kind of approach? For example, can the system be influenced through funding or other incentives? Historically, funding and policy has tended to focus on specific sectors rather than the system as a whole. A case in point was the considerable investment of funds into science centers that occurred as part of the U.K. Millennium funding program, leading to their rapid expansion within the system and the negative impacts on a number of those centers when they proved to be financially unsustainable once capital funding was withdrawn (Wellcome Trust, 2008). Arguably, the community as a whole might have been better served had Millennium funding been framed from a whole-system perspective. For example, rather than investing exclusively in new science center infrastructure what would have happened if funding had been explicitly directed at fostering increased system-wide synergies through collaboration across sectors? What if education providers across the community - both formal and informal-had been explicitly charged with and rewarded for encouraging all of the learners they engaged with to utilize other institutions within the community? Our point here is that funders and institutions would be well served by framing decisions equally from a bottom-up perspective, as is often done when trying to increase representation by specific historically excluded groups or specific learning outcomes and from a more, systemic top-down view, such as might result from supporting efforts to create enduring collaboration and cross- system engagement. In theory, developing an engaged, scienceinterested public is more likely to happen when the all of the entities within a community, both those on the delivery end as well as those on receiving end, operate from a set of shared understandings and goals. 
To this end, it is widely assumed that since schooling is compulsory and informal experiences are voluntary that "access" to science education is a limiting variable in the latter domain. The reality is that formal education, though compulsory does not currently equally serve all citizens any more than does informal. Interest and engagement in science drops precipitously after 10-12 years of age and these declines are disproportionately true in children who do not have access to supportive out-of-school experiences but do continue to participate in the formal education system, suggesting that schooling alone is not sufficient to support a scientifically interested and engaged citizenry (cf. Archer et al., 2012; Falk \& Needham, 2013; Tai et al., 2006). In other words, it is likely that quality, as well as access, is unlikely to be resolved by the current fractured, primarily school-focused approach. It seems reasonable to assume that taking a more systemic approach to public science education, one that equally focuses on in- and out-of-school experiences, is likely the best hope for creating a truly level educational playing field.

\section{Final Thoughts}

In conclusion, this analysis has begun to delve for the first time into defining the structure and functioning of an entire, large-scale science education system, in particular the U.K. science education community. Although the focus of this study was the United Kingdom, we feel that the approach, findings, and recommendations have implications internationally and are worthy of further exploration. Our efforts to begin to define the functional niches within a science education community revealed the need for more complex and nuanced measures. Because of the limitations in our measures of niche, our understanding of the structure of this, and by extension other systems remains quite preliminary. We also understand that using only a single method - an online questionnaire - plus limitations in the design of that instrument and our sampling protocols resulted in gaps in our understanding. However, our goal was to identify major interrelationships and perceptions held by individuals working within the system and to develop a first-order approximation of what was happening in the system; this we did. Similarly, although this investigation offered up only the most rudimentary understanding of the diversity and resilience of the U.K. science education community, we feel that our efforts effectively pointed the way to possibilities for achieving these understandings in the future.

Managing a complex system like a science education community to enhance its diversity and resilience will not be easy. We know that in heavily managed systems improvement efforts are too often imposed externally and precipitously, rather than allowed to arise through more gradual, internally driven processes (Zonneveld \& Forman, 1990). As a consequence, systems become unduly fragile and vulnerable to stresses and perturbations (e.g., in the case of biological communities, pest or disease outbreaks; Chou, 1981); the same has been found to be the case of human systems (e.g., during economic downturns; Mahonge, 2010). Thus, if the ultimate goals of a science education system are both diversity and resilience, managers must understand the properties that enable communities to maintain their integrity in the face of changing conditions and intervention. If we are to manage science education across entire countries and communities to maximize their effectiveness at supporting lifelong public science literacy and engagement, we will need 
to support diversification of the entities engaged in the science education enterprise at all points in the system and improved reciprocal relationships between those entities. We will also stand to benefit by identifying and supporting keystone associations, and generally rewarding, financially and otherwise, collaboration and synergistic approaches. Clearly, this is not something that our current knowledge base permits.

In addition to the need for more strategic, systems thinking, there is a critical need for more systems-oriented research to support such management efforts. This study represents a starting point for this type of systemic management research. Wise education management decisions will require a deeply informed understanding of community structure and function and this work lays a preliminary conceptual foundation on which this type of deeper understanding can be built.

\section{APPENDIX: SCIENCE LEARNING SURVEY TO PROVIDERS 1.1 Section One: About Your Organisation}

In this section we would like to find out about your organisation.

1. Please complete the box below.

2. Which of the following best describes your organisation? (please tick one box only).

Organisation

Your Job Title

Organisation Type

Please Tick

Provider of in-school STEM activities (during or outside school hours)

Community group/Hobby club/Sports club

Electronic media producer - e.g., websites, games, videos

Learned society

Library

Park, Nature centre or Field centre

Provider of teacher CPD

Publisher of printed books and magazines

School

Science museum 
Science and discovery centre

Theatre group

University

Zoo/Aquarium

Other - please describe

\subsection{Section Two: Your Activities and Who You Collaborate With}

This section explores the services and activities that your organisation provides, and the organisations you collaborate with.

3. What type of organisations do you collaborate with when delivering your services, and how often do you collaborate with them? Please complete the box below.

\section{Jrganisation Type}

Please Tick Only One Option for Each Sectc

Never

Occasionally

iducation Org. (a science Organization or business primarily focusing n educational enrichment)

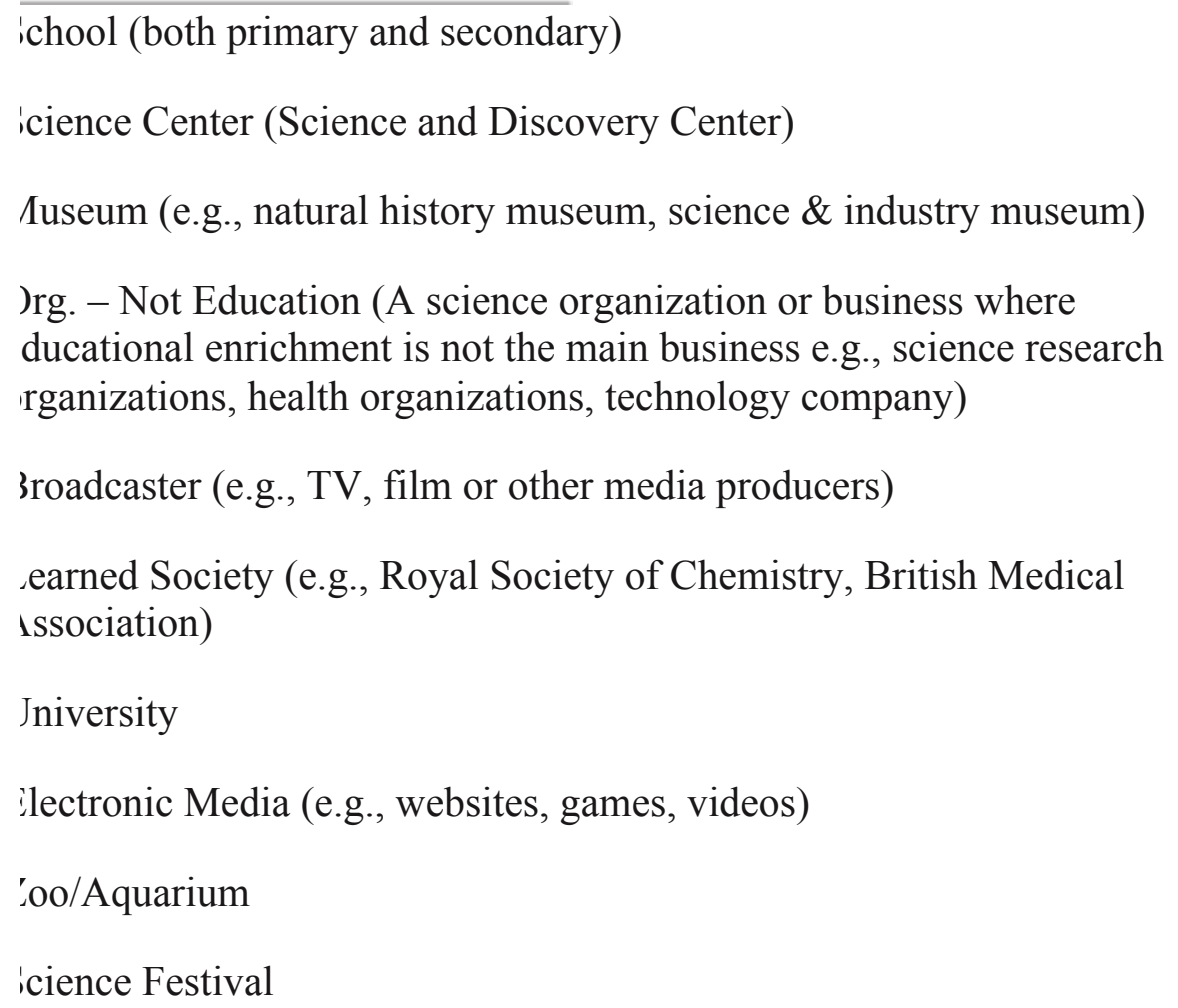


Iobby Club (also Community Groups or Sports Clubs)

Jature Center (also Parks or Field Centers)

heater Group

ibrary

'ublisher (of printed science books and magazines)

)ther (if you feel your organization does not fit one of the above ategories)

iducation Org. (a science 0rganization or business primarily focusing n educational enrichment)

4. Please describe the nature of your collaboration with each of the organisations you work with, by completing the box below for each of the partners you often and most regularly collaborate with. In this question, the term 'resources' refers to any physical resource or people who provide services.

$N B$ - the respondents will be presented with a list of organisation types which only includes those reported as 'Often' and 'Regularly' collaborate with. So have deleted the 'None/Do not collaborate' column

Jrganisation Type

We always use THEIR resources

Please Tick One for Each Sector

\section{We mostly use} THEIR resources

\section{We BOTH}

provide resources
WE mostly provic resources

\author{
iducation Org. (a science \\ rganization or business primarily \\ ocusing on educational \\ nrichment) \\ ichool (both primary and \\ econdary) \\ icience Center (Science and \\ )iscovery Center) \\ Museum (e.g., natural history \\ auseum, science \& industry \\ auseum) \\ )rg. - Not Education (A science
}


rganization or business where ducational enrichment is not the aain business e.g., science esearch organizations, health rganizations, technology ompany)

3roadcaster (e.g., TV, film or other aedia producers)

.earned Society (e.g., Royal iociety of Chemistry, British Medical Association)

Jniversity

Ilectronic Media (e.g., websites, ames, videos)

'oo/Aquarium icience Festival

Hobby Club (also Community Groups or Sports Clubs)

Nature Center (also Parks or Field Centers)

Theater Group

Library

Publisher (of printed science books and magazines)

Other (if you feel your organization does not fit one of the above categories) 
lucation Org. (a science Organization or business primarily focusing on ucational enrichment)

hool (both primary and secondary)

ience Center (Science and Discovery Center)

useum (e.g., natural history museum, science \& industry museum)

:g. - Not Education (A science organization or business where

ucational enrichment is not the main business e.g., science research

ganizations, health organizations, technology company)

oadcaster (e.g., TV, film or other media producers)

sarned Society (e.g., Royal Society of Chemistry, British Medical

ssociation)

aiversity

ectronic Media (e.g., websites, games, videos)

o/Aquarium

:ience Festival

5. Using the following list of organisation types that offer science-related programs, please tick the five organisation types which you consider contribute the MOST to science learning in the UK, and the five which contribute LEAST for audiences 19 years and younger in the UK.

Hobby Club (also Community Groups or Sports

Clubs)

Nature Center (also Parks or Field Centers)

Theater Group

Library

Publisher (of printed science books and magazines)

Other (if you feel your organization does not fit one of the above categories)

\subsection{Your Audiences}

This section explores the audiences you deliver services to, and your experience of 
engaging with different groups.

6. Who are the main audiences for your services - who do you provide services to?

Please complete the box below for each service you provide.

\section{Service/Activity}

Children aged under 5

Children aged 5-11

Young people aged 12 to 16

Young people aged 16-18

Families

Adults aged 19 and above

Schools - Primary

Schools - Secondary

Other - please describe

\section{Main Audience}

\section{Secondary Audience}

Not an Audier

The above will be repeated for each service listed in Question 8

\subsection{Your Contact Details}

If you would be prepared to take further part in this study, or be contacted again by the study team, please provide your contact details below.

THANK AND CLOSE

Respondent

Name

Email

Telephone

Special thanks to the Wellcome Trust for support of this research, in particular Sir John Holman. Thanks also to GHK for collaboration on data collection. The authors state they have no conflict of interest; no interest or relationship, financial, or otherwise, that might be perceived as influencing an author's objectivity with regard to this article. 


\section{REFERENCES}

Alexander, K. L., Entwisle, D. R., \& Olson, L. S. (2007). Lasting consequences of the summer learning gap. American Sociological Review, 72, 167 - 180.

Archer, L., DeWitt, J., Osborne, J., Dillon, J., Willis, B., \& Wong, B. (2012). Science aspirations and family Habitus: How families shape children's engagement and identification with science. American Educational Research Journal, 49, 881 - 908.

Ashby, W. R. (1946). The behavioural properties of systems in equilibrium. American Journal of Psychology, 59, $682-686$.

Ashby, W. R. (1947). Principles of the self-organizing dynamic system. Journal of General Psychology. 37, $125-128$.

Ashby, W. R. (1956). An introduction to cybernetics. London: Chapman \& Hall. Barab, S. A., \& Kirshner, D. (2001). Rethinking methodology in the learning sciences. Journal of the Learning Sciences, 10(1\&2), $5-15$.

Barker, R. G. (1968). Ecological psychology. Palo Alto, CA: Stanford University Press.

Barker, R. G., \& Wright, H. F. (1951). One boy's day: A specimen record of behavior. New York: Harper Brothers.

Barker, R. G., \& Wright, H. F. (1954). Midwest and its children: The psychological ecology of an American town. Evanston, IL: Harper \& Row.

Barron, B. (2006). Interest and self-sustained learning as catalysts of development: A learning ecology perspective. Human Development, 49, 193 - 224.

Bastian M., Heymann S., \& Jacomy, M. (2009). Gephi: An open source software for exploring and manipulating networks. Presented at International AAAI Conference on Weblogs and Social Media. Retrieved May 16, 2014, fromhttps://www.aaai.org/ocs/index.php/ICWSM/09/paper/view/154/1009.

Bathgate, M. E., Schunn, C. D., \& Correnti, R. (2014). Children's motivation toward science across contexts, manner of interaction, and topic. Science Education, 98(2), 189 215 .

Bell, P., Lewenstein, B., Shouse, A., \& Feder, M. A. (2009). Learning sciences in informal environments: People, places and pursuits. Washington, DC: National Academies Press.

Bøe, M. V. (2011). Science choices in Norwegian upper secondary school: What matters? Science Education, 96(1), 1 - 20. 
Bronfenbrenner, U. (1979). The ecology of human development: experiments by nature and design. Cambridge, MA: Harvard University Press.

Brown, J. S. (2000). Growing up digital: How the web changes work, education, and the ways people learn. Change: The Magazine of Higher Learning, 32(2), 11 - 20.

Brown, K., \& Keast, R. (2003). Citizen-government engagement: Community connection through networked arrangements. Asian Journal of Public Administration, 25(1), 107 131.

Chou, C. K. S. (1981) Monocultures, species diversification and disease hazards in forestry. New Zealand Journal of Forestry, 26(1), 20 - 36

Dale, V. H. (2003). Ecological modeling for resource management. New York: Springer.

Dawson, E. (2012). Science and the inclusive society: How do UK minority ethnic groups experience public engagement with science and technology? Unpublished doctoral thesis. King's College, London.

Department for Culture Media and Sport. (2011). Taking Part: The national survey of culture, leisure and sport. London: Author.

Downey, D. B., Von Hippel, P. T., \& Broh, B. A. (2004). Are schools the great equalizer? Cognitive inequality during the summer months and the school year. American Sociological Review, 69(5), 613 - 635.

Edwards, C. (2009). Resilient nation. London: DEMOS. Falk, J. H. (1976) Energetics of a suburban lawn ecosystem. Ecology, 57(1), $141-150$.

Falk, J. H., \& Dierking, L. D. (1992). The museum experience. Washington, DC: Whalesback.

Falk, J. H., \& Dierking, L. D. (2010). The 95\% solution: School is not where most Americans learn most of their science. American Scientist, 98, 486 - 493.

Falk, J. H., \& Dierking, L. D. (2013). The museum experience revisited. Walnut Creek, CA: Left Coast Press.

Falk, J. H., Dierking, L. D., Needham, M. D., \& Prendergast, L. (2014). The International Science Centre Impact Study: Final Report. Technical Report. Corvallis, OR: John H Falk Research.

Falk, J. H., Osborne, J., Dierking, L. D., Dawson, E., Wenger, M., \& Wong, B. (2012). Analysing the UK science education community: The contribution of informal providers. London: Wellcome Trust. Retrieved May 16, 2014, from http://www.wellcome.ac.uk/stellent/groups/corporatesite/@msh_peda/documents/web_ document/wtp040860.pdf. 
Falk, J. H., \& Needham, M. (2011). Measuring the impact of a science center on its community. Journal of Research in Science Teaching, 48(1), $1-12$.

Falk, J. H., \& Needham, M. D. (2013). Factors contributing to adult knowledge of science and technology. Journal of Research in Science Teaching, 50(4), 431 - 452.

Falk, J. H., Randol, S., \& Dierking, L. D. (2012). Understanding the informal science education landscape: An exploratory study. Public Understanding of Science, 21(7), 865 -874 .

Gell-Mann, M. (1994). The quark and the jaguar: Adventures in the simple and the complex. San Francisco: W. H. Freeman.

Hannan, M., \& Freeman, J. (1989). Organizational ecology. Cambridge, MA: Harvard University Press. HM Treasury. (2004). Science \& innovation investment framework: 2004 - 2014. London: Her Majesty's Stationary Office. Holland, J. E. (2006) Studying complex adapative systems. Journal of Systems Science \& Complexity, 19(1),1-8.

Horrigan, J. (2006). The Internet as a resource for news and information about science. Washington, DC: Pew

Internet \& American Life Project. House of Lords. (2000). Science and society. London: Her Majesty's Stationary Office. Hudson, B. (2004). Using ecological frameworks to analyze network partnerships. Public Management Review, 6(1), 75 - 94.

Hupbach, A., Hardt, O., Gomez, R., \& Nadel, L. (2008). The dynamics of memory: Context-dependent updating. Learning \& Memory, 15(8), 574 - 579.

Ito, M., Baumer, S., Bittanti, M., Boyd, D., Cody, R., Herr-Stephenson, B., et al. (2013). Hanging out, messing around, and geeking out: Kids living and learning with new media. Cambridge, MA: MIT Press.

Jackson, N. (2013). Learning ecologies. Lifewide Magazine. Retrieved November 6, 2013, from http://www.normanjackson.co.uk/uploads/1/0/8/4/10842717/chapter c4 learning ecology narratives.pdf.

Jacobson, M. J., \& Wilensky, U. (2006). Complex systems in education: Scientific and educational importance and research challenges for the learning sciences. Journal of the Learning Sciences, $11-34$.

Kaplan, S., \& Kaplan, R. (1982). Cognition and environment. New York: Praeger. Klijn, E., \& Koppenjan, J. (2000). Public management and policy networks: Foundations of an ecological network approach to governance. Public Management, 2(2), 135 - 158.

Korpan, C. A., Bisanz, G. L., Boehme, C., \& Lynch, M. A. (1997). What did you learn outside of school today? Using structured interviews to document home and community activities related to science and technology. Science Education, 81, $651-662$. 
Lemke, J. L., Lecusay, R., Cole, M., \& Michalchik, V. (2012). Documenting and assessing learning in informal and media-rich environments. Boston: MIT Press.

Lemke, J. L., \& Sabelli, N. H. (2008). Complex systems and educational change: Towards a new research agenda. Educational Philosophy and Theory, 40(1), 118 - 129.

Levins, S. A., (1998). Ecosystems and the biosphere as complex adaptive systems. Ecosystems, 1, $431-436$.

Lyons, T., Quinn, F., Rizk, N., Anderson, N., Hubber, P., Kenny, J., et al. (2012). Starting out in STEM: A study of young men and women in first year science, technology, engineering and mathematics courses. Armidale, New South Wales, Australia: SiMEER National Research Center.

Mahonge, C. (2010). Co-managing complex social-ecological systems in Tanzania. The case of Lake Jipe wetland (e-book). Wageningen, The Netherlands: Wageningen Academic Publishers.

Maroulis, S. J., Guimera', R., Petry, H., Stringer, M. J., Gomez, L. M., Amaral, L. A. N., et al. (2010). Complex systems view of educational policy research. Science, 330(6000), $38-39$.

Mason, M. (2008). What is complexity theory and what are its implications for educational change? Educational Philosophy and Theory, 40(1), 35 - 49.

McAslan, A. R. R. (2010). The concept of resilience: Understanding its origins, meaning and utility. Adelaide, South Australia, Australia: Torrens Resilience Institute.

McLeroy, K., Bibeau, D., Steckler, A., \& Glanz, K. (1988). An ecological perspective on health promotionprograms. Health Education Quarterly. 15(4), $351-377$.

Miller, J. D. (2010). Adult science learning in the Internet era. Curator, 53, $191-208$.

Morin, P. J. (2011). Community ecology. New York: Wiley-Blackwell Press.

Naheem, S., \& Li, S. (1997). Biodiversity enhances ecosystem reliability. Nature, 290, $507-509$.

National Science Board. (2012). Science and engineering indicators: 2011. Washington, DC: U.S. Government Printing Office.

Organization for Economic Co-operation and Development. (2012). PISA in focus 18: Are students more engaged when schools offer extracurricular activities? Paris: Author.

Ormerod, M. B., \& Duckworth, D. (1975). Pupils' attitudes to science. Slough, England: NFER. Paine, R. T. (1995). A conversation on refining the concept of keystone species. Conservation Biology, 9(4), 962 - 964. 
Ripple, W. J., \& Beschta, R. L.(2004). Wolves, elk, willows, and trophic cascades in the upper Gallatin range of Southwestern Montana, USA. Forest Ecology and Management, $200,161-181$.

Simberloff, D., \&.Dayan, T. (1991). The guild concept and the structure of ecological communities. Annual Review of Ecological Systems, 22, 115 - 143. Smith, D. W., Petersen, R. O., \& Houston, D. B. (2003). Yellowstone after wolves. Bioscience, 53(4), $330-340$.

Socolow, R., Andrews, C., Berkhout, F., \& Thomas, V. (Eds.) (1994). Industrial ecology and global change. Cambridge, England: Cambridge University Press.

Steiner, C. F., Long, Z., Krumins, A., \& Morin, P. (2006). Population and community resilience in multitrophic communities. Ecology, 87(4), 996 - 1007.

St. John, M., \& Perry, D. (1993). A framework for evaluation and research: science, infrastructure and relationships. In S. Bicknell \& G. Farmelo (Eds.), Museum visitor studies in the 90s (pp. 59 - 66). London: Science Museum.

Stocklmayer, S. M., Rennie, L. J., \& Gilbert, J. K. (2010). The roles of the formal and informal sectors in the provision of effective science education. Studies in Science Education, 46(1), $1-44$.

Tai, R. H., Qi Liu, C., Maltese, A. V., \& Fan, X. (2006). Planning early for careers in science. Science, 312, $1143-1145$.

Tal, T., \& Dierking, L. D. (2014). Editorial: Learning science in everyday life. Journal for Research in Science Teaching, 51(3), $251-259$.

Tilman, D., Lehman, C. L., \& Thomson, K. T. (1997). Plant diversity and ecosystem productivity: theoretical considerations. Proceedings of the National Academy of Sciences of USA, 94, $1857-1861$.

von Bertalanffy, K. L. (1968). General system theory: Foundations, development, applications. New York: George Braziller.

Walker, B. H., \& Salt, D. (2005). Resilience thinking: sustaining ecosystems and people in a changing world. Washington, DC: Island Press.

Wellcome Trust (2008). Millennium science centres impact assessment report. Executive summary. London: Wellcome Trust.

Wicker, A. (1979). An introduction to ecological psychology. New York:

Brooks/Cole. Winch, P. (2012). Ecological models and multilevel interventions: Health behavior change at the level of individuals, households and communities. Baltimore, MD: Johns Hopkins Press.

Zonneveld, I. S., \& Forman, R. T. T. (1990). Changing landscapes: An ecological 
perspective. New York: Springer Verlag. 